\title{
From innovation-as-usual towards unusual innovation: using nature as an inspiration
}

John P. Ulhøi(D)

Correspondence: jpu@mgmt.au.dk Aarhus University, Aarhus C, Denmark

\begin{abstract}
Innovation-as-usual employs synthetic input as the key source of inspiration to bring about innovations, whereas unusual innovation is inspired by designs in nature. The use of nature as a key stimulus for innovation represents a fundamental shift in management and business studies. It involves the translation of natural designs into cross-domain and ad hoc synthetic designs. This paper examines and discusses the phenomenon of biomimetics and different examples of its application. Efficient translation of biomimetics involves the critical processes of exploration, explanation and exploitation. This paper discusses a practical case of biomimetic translation and identifies some critical and greatly understudied translational processes. The paper proposes techniques to correct existing translational imperfections and to establish theoretical bridging points to responsible management practices. Before concluding, research and managerial implications are briefly addressed.
\end{abstract}

Keywords: Innovation, Design, Nature, Biomimetics, Scientific translation, Bombardier beetle

JEL: M13, O31, O32

\section{Introduction}

Nature-inspired design has attracted human interest since prehistoric times, when hunters and gatherers produced spears from the teeth of different animals and applied hunting techniques inspired by animals they admired (Kennedy, Fecheyr-Lippens, Hsiung, Niewiarowaki, \& Kolodziej, 2015). Narratives from Greek mythology describe how Icarus created waxed feather wings to try to escape his captivity on Crete. Compared to the short development time of synthetic (fabricated) designs, the evolutionary timescale of natural designs involves longer periods of incremental improvements. This feature is appreciated in the field of biomimetics or biomimicry, as it is generally assumed that designs brought about by biological evolution offer fit solutions. Bio originates from the Greek language (bios) and means life. Mimetics and mimicry come from mimesis, which signifies imitation. Notwithstanding that biomimetics and biomimicry are often used synonymously in the literature. Iouguina, Dawson, Hallgrimson, and Smart (2014) have proposed that a distinction can be made. Interestingly, however, in their study of experts' use of the two terms, they documented that the majority of

(c) The Author(s). 2020 Open Access This article is licensed under a Creative Commons Attribution 4.0 International License, which permits use, sharing, adaptation, distribution and reproduction in any medium or format, as long as you give appropriate credit to the original author(s) and the source, provide a link to the Creative Commons licence, and indicate if changes were made. The images or other third party material in this article are included in the article's Creative Commons licence, unless indicated otherwise in a credit line to the material. If material is not included in the article's Creative Commons licence and your intended use is not permitted by statutory regulation or exceeds the permitted use, you will need to obtain permission directly from the copyright holder. To view a copy of this licence, visit http://creativecommons.org/licenses/by/4.0/. 
interviewed biomimetic experts believe the two words to be equivalent. Further, the authors introduce the term biologically informed to denote informed interpretation of biological research to address human challenges for the purpose of innovation (ibid). Nevertheless, Iouguina et al. (2014) did not succeed in providing an etymologically grounded distinction between biomimicry and biomimetics. Several authors in the field have also explicitly indicated that they perceive the two words as being synonymous (see for example Blok \& Gremmen, 2016).

Biomimetics vary from employing natural design exclusively as a visual stimulus for the development of synthetic designs towards scientific translation of nature's design or design principles for subsequent synthetic applications. Biomimetics has gained particular prominence in fields such as biology and engineering sciences, where the number of biomimetic publications has increased from a few to several thousand papers a year (Lepora, Verschure, \& Prescott, 2013). An extensive review of such publications from 1995 to 2011 identified about 18,000 papers published in scholarly journals (57\%) and conference proceedings (43\%). Although biomimetics has adopted expressions from the corporate vocabulary, such as 'cost performance' and 'deliverables' (e.g., Fisch, 2017, p. 804), the field of business studies has paid surprisingly little attention to biomimetics (Ulhøi 2015) or to translational research (Cremades, Balbastre-Benavent, \& Domínguez, 2015) - particularly taking recently published market expectations into consideration. Between 2005 and 2008, the market for products and construction projects that applied biomimetic solutions was estimated to be above USD 1.5 billion. By 2025, industry analysts foresee that the market for products and services within biomimicry will increase to USD 1 trillion. In the US alone, a USD 35 billion market with over 1.6 million new job opportunities is expected (Hwang et al., 2015). It is estimated that medical biomimetics will have a market potential of USD 425 billion by 2024 (Global Market Insight, 2018).

Two interlinked research questions have guided this study. The first question asks which design solutions from nature have to offer to synthetic solutions (i.e., what makes natural design unusual or different from synthetic design?). This question is used to introduce biomimetics to an audience assumed to have little or no previous familiarity with this phenomenon. Having defined and framed biomimetics, some of the applicative scope and diversity of biomimetics are sketched out. The answer to this question shows that biomimetics offers interesting potential applications for synthetic design. It further indicates that existing biomimetic translation models do not account for the entire process of translation from idea to practical and commercial use and that previous suggestions to use biomimetics for innovation suffer from a lack of attention towards the early explorative and, in particular, the late exploitative process of translation. The wider potential of biomimetics is severely limited if particularly the latter process of translation is overlooked.

This aspect is pursued in the second research question-what are the essential factors during the commercial translation process of natural designs? In answering this question, the paper probes deeper into the commercial processes of the overall process of biomimetic translation. Having shown that existing translation models do not allow for exploiting the full potential of biomimetic translations, the paper clarifies what is needed to increase the exploitation of commercial potential. Not all biomimetic ideas may be ready for a translation. Some may, for example, require additional exploration 
and explanation to account fully for all the scientific details. Others may not yet have been acknowledged for their commercial potential. Both situations expose critical imperfections in contemporary translational models, and this study attempts to correct them. However, biomimetics is not limited to application for industrial and tangible artefacts. If applied in the pharma and health sectors, the speed of lab-to-industry translation becomes of the uttermost importance. In such cases, not only entrepreneurial and/ or commercial expertise and agency are required, but so are innovative organizational arrangements (as shown in the paper) to accelerate the entire processes of translation from idea to commercialization.

This paper offers two contributions. First, the paper introduces biomimetics to an audience likely to be unfamiliar with biomimetics (business scholars). This is important, as this audience is of high importance in securing the full exploitation of biomimetics' wider application potential. It does so by introducing important definitions and properties of biomimetics and by discussing key applicative areas of biomimetic translations. The study shows that biomimetics holds interesting potential for innovation (synthetic designs). Limitations are identified by examining state-of-the-art literature on biomimetics translation. It is necessary to correct these limitations to adequately account for efficient translation in terms of scientific exploration, theoretical explanation and commercial exploitation.

Some biomimetic ideas are not necessarily ready for immediate translation, but require additional scientific and/or technical explorations before being sufficiently understood. This leads to the study's second contribution, which relates to proposing concrete tactics to correct identified imperfections in existing biomimetic translation theory. Existing theory has failed to pay sufficient attention to two translational phases: (i) a pre-phase of additional scientific exploration and explanation, which is sometimes needed and, more importantly, (ii) a crucial and lacking commercial exploitation phase that helps secure efficient exploitation-and thus practical uses of-biomimetic translations. Originating from a thorough analysis of the bombardier beetle case in a context of business innovation and development, this paper discusses a practical case of biomimetics that goes through an entire process of translation. This analysis establishes a point of departure from which to propose concrete tactics to overcome the identified imperfections in the mainstream biomimetic translation model. Its extension further underscores the importance of including all critical activities necessary for a successful biomimetic translation process. If the commercial phase is left out (i.e., if a project does not get beyond the scientific and engineered translation), scientific translations are likely to be of interest only to scientists and engineers involved in the scientific explorations and explanations.

The time and effort associated with the complete translation of the scientific principles explaining the bombardier beetle's defence system took a surprisingly long time. Translation time, however, can be critical when applied in sectors such as pharma and medical businesses. This being taken into account, the paper draws on recent development in the field of translational medicine to find ways to reduce the time from bench to bed. Recent development in this field shows how translation, as demonstrated by the Myelin Foundation, can significantly reduce the time to market and thus increase the commercial potential of biomimetic exploitation in pharmaceutical and health sectors. 
The overall structure of the paper reflects the specific order and sequencing of the three research questions. Next, the phenomenon of biomimetics is presented. Key definitions and properties of biomimetics are introduced, and examples of key areas of biomimetic translations are singled out. Following this, the mainstream phase-based design model adopted in the field of biomimetic translation is outlined. Then, based on secondary data, a practical case study of biomimetic translation is examined, involving the unique spray technique of the bombardier beetle. In this case, all critical processes of biomimetic translation, from scientific exploration and explanation to commercial exploitation, have been used. Based on a thorough examination of the bombardier beetle case, a set of critical and highly understudied translational constituents have been identified. Drawing on translational research in medicine, this section further discusses an innovative approach to commercial translation capable of accelerating this critical constituent of the overall translation process while at the same time demonstrating the importance of interorganizational collaboration. Before concluding, key avenues for research and practical implications are briefly sketched out.

\section{Biomimetics: definitions and areas of application}

It is easy to spot some internationally highly admired synthetic designs inspired by nature. Eye-catching examples include the design of the Sydney Opera House (shells) ${ }^{1}$ in Australia, the Shinkansen bullet train (the Kingfisher's beak ${ }^{2}$ ) in Japan and the Egg Chair $^{3}$ (an incomplete eggshell) in Denmark. The natural sources of inspiration in all three examples are rather obvious. Although there seems to be a widespread consensus among biologists that the inspiration appears to go from biology to the engineering sciences, the roles of the biological and non-biological sciences during the analogue transfer process appear to be less clear. This has also been referred to as a cross-domain analogy (Helms, Vattam, \& Goel, 2009). Attempts at defining a biomimetic system vary across disciplines. Within the natural sciences, disagreement exists with regard to what qualifies as a biomimetic system. Physicists, for example, acknowledge the existence of a biomimetic system if it contains a biological component, whereas biologists demand a complete synthetic mimicry of a biological process (Rawlings, Bramble, \& Staniland, 2012, p. 6675). Some scholars, however, have referred to biomimetics in this way: 'a new and hybrid science is coming into being that crosses the disciplinary boundaries between biology and chemistry' (Bensaude-Vincent et al., 2002, p. 4). Table 1 below displays in chronological order a sample of different disciplines that have engaged in biomimetics/biomimicry translations at different organizational levels.

\footnotetext{
${ }^{1}$ In a rare interview included in The Sydney Morning Herald, September 16, 2014, the chief architect Jørn Utzon broke a quarter-century's silence regarding the Sydney Opera House. Although the stimulus to the design did not come from seashells, it was biologically inspired; he was initially inspired to the iconic design when peeling an orange (http://www.smh.com.au/good-weekend/gw-classics/utzon-breaks-his-silence-2014 0904-10c93e.html, retrieved on February 2, 2018).

${ }^{2}$ After the development of the train, severe noise problems were experienced when the high-speed train entered tunnels. It was established that this was due to a shockwave. The inspiration to solve the noise problem caused by the synthetic design was found in a natural design, namely the beak of the kingfisher bird-a skillful bird that hunts by diving from the air into the water at a very high velocity without making any noise. The bio-inspiration not only solved the noise problem, it also entailed a total elimination of the problem and led to an important energy reduction (García-Serna, Pérez-Barrígon, \& Cocero, 2007, p. 12).

${ }^{3} \mathrm{~A}$ picture of the chair is available at http://chairclassic.com/products/Arne_Jacobsen_egg_chair.html. The architect, Arne Jacobsen, was inspired by other designs from nature when designing other classic chairs, such as the Swan Chair (http://chairclassic.com/products/Arne_Jacobsen_Swan_chair.html) and the Ant Chair (http://chairclassic.com/products/Arne_Jacobsen_Ant_chair.html).
} 
Table 1 Definitions, disciplinary origins and organizational levels in chronological order

\begin{tabular}{|c|c|c|c|c|}
\hline Definition & Author(s) & Terminology & $\begin{array}{l}\text { Disciplinary } \\
\text { origin }\end{array}$ & $\begin{array}{l}\text { Organizational } \\
\text { level }\end{array}$ \\
\hline $\begin{array}{l}\text { Studies nature's models and emulates } \\
\text { natural forms, processes, systems and } \\
\text { strategies for solving human problems }\end{array}$ & Benyus (1997) & Biomimicry & $\begin{array}{l}\text { Natural } \\
\text { resource } \\
\text { management }\end{array}$ & System level \\
\hline $\begin{array}{l}\text { A scientific style inspired by } \\
\text { technological considerations and a } \\
\text { fresh look at nature }\end{array}$ & $\begin{array}{l}\text { Bensaude-Vincent, } \\
\text { Arribart, Bouligand, } \\
\text { and Sanchez (2002) }\end{array}$ & Biomimicry & Chemistry & Molecular level \\
\hline A system development tool & $\begin{array}{l}\text { Rice and Martin } \\
\text { (2007) }\end{array}$ & Biomimicry & $\begin{array}{l}\text { Social } \\
\text { sciences }\end{array}$ & Systems level \\
\hline $\begin{array}{l}\text { Biological phenomena for inspiring } \\
\text { solutions to engineering problems }\end{array}$ & Mak and Shu (2008) & Biomimetics & $\begin{array}{l}\text { Engineering } \\
\text { sciences }\end{array}$ & $\begin{array}{l}\text { Conceptual } \\
\text { level }\end{array}$ \\
\hline $\begin{array}{l}\text { Transfer from one or more biological } \\
\text { examples to a technical system }\end{array}$ & $\begin{array}{l}\text { Sartori, Pal, and } \\
\text { Chakrabarti (2010) }\end{array}$ & Biomimetics & $\begin{array}{l}\text { Product } \\
\text { design and } \\
\text { manufacturing }\end{array}$ & Product level \\
\hline $\begin{array}{l}\text { A source of inspiration and a toolkit for } \\
\text { solving practical design problems }\end{array}$ & $\begin{array}{l}\text { Volstad and Boks } \\
(2012)\end{array}$ & Biomimicry & $\begin{array}{l}\text { Engineering } \\
\text { sciences }\end{array}$ & $\begin{array}{l}\text { Industrial } \\
\text { design level }\end{array}$ \\
\hline $\begin{array}{l}\text { An interdisciplinary scientific research } \\
\text { that makes nature a new source of } \\
\text { inspiration }\end{array}$ & $\begin{array}{l}\text { Habib and } \\
\text { Watanabe (2012) }\end{array}$ & $\begin{array}{l}\text { Bio- } \\
\text { inspiration }\end{array}$ & $\begin{array}{l}\text { Engineering } \\
\text { sciences }\end{array}$ & $\begin{array}{l}\text { Technology } \\
\text { level }\end{array}$ \\
\hline $\begin{array}{l}\text { The imitation of a product or process } \\
\text { found in nature }\end{array}$ & $\begin{array}{l}\text { Rawlings et al. } \\
\text { (2012) }\end{array}$ & Biomimetics & Biosciences & Protein level \\
\hline $\begin{array}{l}\text { A field that seeks to interpolate natural } \\
\text { biological mechanisms and structures } \\
\text { into different applications }\end{array}$ & Lurie-Luke (2014) & Biomimicry & $\begin{array}{l}\text { Applied } \\
\text { sciences }\end{array}$ & $\begin{array}{l}\text { Applicational } \\
\text { science level }\end{array}$ \\
\hline $\begin{array}{l}\text { Varying levels of biomimicry (strong } \\
\text { and weak) }\end{array}$ & $\begin{array}{l}\text { Blok and Gremmen } \\
\text { (2016) }\end{array}$ & Biomimicry & $\begin{array}{l}\text { Social } \\
\text { sciences }\end{array}$ & $\begin{array}{l}\text { Philosophical } \\
\text { level }\end{array}$ \\
\hline $\begin{array}{l}\text { Imitate general abstracted mechanisms } \\
\text { that render many natural systems } \\
\text { sustainable for long periods of time }\end{array}$ & Troncale (2016) & Biomimicry & $\begin{array}{l}\text { Systems } \\
\text { engineering }\end{array}$ & Systems level \\
\hline Instantiation of progressive techniques & Fisch (2017) & Biomimicry & $\begin{array}{l}\text { Social } \\
\text { sciences }\end{array}$ & $\begin{array}{l}\text { Philosophical } \\
\text { level }\end{array}$ \\
\hline $\begin{array}{l}\text { The practice of human designers } \\
\text { mimicking an organism, behaviour } \\
\text { aspects of ecosystems }\end{array}$ & Zari (2017) & Biomimetics & Architecture & $\begin{array}{l}\text { Industrial } \\
\text { design level }\end{array}$ \\
\hline
\end{tabular}

Lurie-Luke's recent review of the literature on biomimetic translations showed that material translations account for about half of the extant publications (Lurie-Luke, 2014). She further categorized material design into four groups: smart materials inspired by nature's ability to react and change in response to external stimuli; surface modifications, which include novel surface topographies with improved functions; material architectures, which feature novel shapes and structural arrangements; and technologies that are based on enhancing existing systems using the specific parameters of an adaptation (p. 1496). Locomotion-inspired biomimetics came second and were classified into three groups (p. 1499): improvements based on movement kinetics, improvements based on release mechanisms (means of dispersal across an environment), and improvements based on structural configuration (energy-efficient shapes). Table 2 exhibits a variety of biomimetics translations.

Different classifications of bio-inspired design processes have been proposed in the literature. They vary from the implementation of specific properties and transfer of form behaviour to different situations wherein no apparent similarity exists between the biological phenomenon and the engineered design (Mak \& Shu, 2008). One example is Troncale's study (Troncale, 2016) on biomimetics at a systems level. Other 
Table 2 Inspirations and areas of application in chronological order

\begin{tabular}{|c|c|c|c|}
\hline Application & Author(s) & Biological inspiration & $\begin{array}{l}\text { Disciplinary } \\
\text { origin }\end{array}$ \\
\hline Artificial surfaces & $\begin{array}{l}\text { Barthlott and Neinhuis } \\
\text { (1997) }\end{array}$ & $\begin{array}{l}\text { Natural system for delivering a } \\
\text { periodic pulsed spray }\end{array}$ & $\begin{array}{l}\text { Engineering } \\
\text { sciences }\end{array}$ \\
\hline Anti-viral software & Rice and Martin (2007) & Biological models & $\begin{array}{l}\text { Information } \\
\text { systems }\end{array}$ \\
\hline $\begin{array}{l}\text { Gas turbine igniters } \\
\text { (aerospace) }\end{array}$ & $\begin{array}{l}\text { Beheshti and } \\
\text { Mcintosch (2007) }\end{array}$ & $\begin{array}{l}\text { Natural system to deliver a periodic } \\
\text { pulsed spray }\end{array}$ & $\begin{array}{l}\text { Engineering } \\
\text { sciences }\end{array}$ \\
\hline $\begin{array}{l}\text { Artificial molecules } \\
\text { (biomedical applications) }\end{array}$ & $\begin{array}{l}\text { Jang, Selim, Lee, and } \\
\text { Kang (2008) }\end{array}$ & Biological agents & Chemistry \\
\hline $\begin{array}{l}\text { A problem-solving } \\
\text { methodology for interior } \\
\text { architecture }\end{array}$ & El-Zeiny (2012) & Biomimicry & Architecture \\
\hline $\begin{array}{l}\text { Optimization of fluid } \\
\text { transportation }\end{array}$ & Kim and Busch (2012) & Natural drinking strategies & $\begin{array}{l}\text { Mathematics } \\
\text { and mechanics }\end{array}$ \\
\hline $\begin{array}{l}\text { Scaleable multiscale } \\
\text { patterning technology }\end{array}$ & Bae et al. (2014) & $\begin{array}{l}\text { Multiscale, hierarchical patterned } \\
\text { surfaces (butterfly wings, gecko } \\
\text { lizards) }\end{array}$ & $\begin{array}{l}\text { Advanced } \\
\text { materials }\end{array}$ \\
\hline $\begin{array}{l}\text { Lessons for human } \\
\text { organizations }\end{array}$ & Fewell (2015) & Social behaviour of insects & $\begin{array}{l}\text { Social dynamics } \\
\text { and complexity }\end{array}$ \\
\hline $\begin{array}{l}\text { Optimization of technical } \\
\text { pumping systems }\end{array}$ & $\begin{array}{l}\text { Bach, Schmich, } \\
\text { Masselter, and Speck } \\
\text { (2015) }\end{array}$ & Natural pumping techniques & $\begin{array}{l}\text { Materials and } \\
\text { biomechanics }\end{array}$ \\
\hline $\begin{array}{l}\text { A model of bio-inspiration } \\
\text { for creative design }\end{array}$ & $\begin{array}{l}\text { Salgueiredo and } \\
\text { Hatchuel (2016) }\end{array}$ & Bioinspired design & $\begin{array}{l}\text { Concept- } \\
\text { knowledge } \\
\text { design }\end{array}$ \\
\hline $\begin{array}{l}\text { A new way of thinking and } \\
\text { acting ecologically }\end{array}$ & $\begin{array}{l}\text { Blok and Gremmen } \\
\text { (2016) }\end{array}$ & Biomimicry & Social sciences \\
\hline Actuators for robotics & Hu et al. (2017) & Human's flick finger behaviour & Nanosciences \\
\hline $\begin{array}{l}\text { Anti-corrosion/erosion } \\
\text { surfaces }\end{array}$ & Zhang et al. (2017) & Desert scorpion (its micro-structure) & $\begin{array}{l}\text { Surfaces in } \\
\text { motion }\end{array}$ \\
\hline
\end{tabular}

examples are the social organization of insects, which involves collective efforts and flexible work organization (Fewell, 2015); the collective decision-making in colonies of honey bees (Seeley, 2003); actuations to create life-like motion (Habib \& Watanabe, 2012); a robust surface that repels even complex fluids under harsh conditions (Wong et al., 2011); and specific properties or living organisms such as, for example, the adhesive property of gecko-feet hair (Autumn et al., 2000). Of relevance to the human principles of organization, analyses of the behaviour of large-scale social insects have led to attempts to extract a generalized set of organizing principles (Fewell, 2015): large-scale societies organize themselves effectively based on diverse local interactions rather than via external or centralized direction (reflecting distributed systems); cumulative effects of local interactions generate non-linear changes in behaviour (self-organization); and local effects scale up into group-level effects that are more than the summation of individual abilities (synergy). However, biological systems are often not immediately accessible, implying that the investigator needs to focus on models of biological systems (Sartori et al., 2010).

Rice and Martin (2007) examined how complex biological systemic processes might be applied to improve the innovation system and processes in a high-technology field such as anti-virus software development to change it from being predominantly reactive to becoming proactive. In so doing, the authors propose a theoretical framework 
consisting of different sets of steps: define the problem, analyze and identify the desired functions, select the premium biological model, develop and test the taxonomy of designs, and review the produced systems or products. They developed a theoretical platform relating to biological immune systems and proposed parallels with computer network immunity and antiviral designs (p. 211). Other research on complex scientific knowledge transfer has shown that such transfer processes do not follow a unidirectional process of knowledge transfer. A study of science-based and entrepreneurial firms and their collaborations with university scientists with the aim of producing joint knowledge production documented that such collaborations seem to be associated with the highly dynamic and recursive processes of technical knowledge exchanges (Ulhøi et al., 2012). Additional scholars have examined key determinants generally involved in the knowledge translation process. Cremades et al. (2015), for example, found in their study that the translation process involves three generic elements: knowledge creation, organizational learning and knowledge transfer (p. 366). First, they emphasized the importance of the spiralling and interactive nature of the relationship between tacit and explicit knowledge. Second, they underscored the critical process of integrating individual and group learning and identified the process through which knowledge is exchanged from one organizational actor to another.

\section{Translational approaches in biomimetics}

Nature-inspired design comprises a variety of approaches, ranging from the architect drawing inspiration from nature's visual design features to fully understanding the scientific principles behind biomimetic inspiration. Fisch (2017), for example, points out that biomimetics, as introduced by Benyus (1997), has been referred to as a methodology and technological apparatus for identifying interesting functionalities and processes from nature, which can be mimicked and translated into technological innovations. It thus follows that the basic methodological idea supporting biomimetic design is to analyze and extract fundamental principles of a biological process and translate them into a technical solution to the problem at hand. Helms et al. (2009) have examined biologically inspired design and identified the following phases involved in it: definition of a problem, redefinition of the questions from the perspective of biology, a search for solutions to biological problems, definition of the principles of the functional operation and solutions, and extraction of biological principles. These phases are depicted in Fig. 1, which sketches out the key phases of scientific translation, see below:

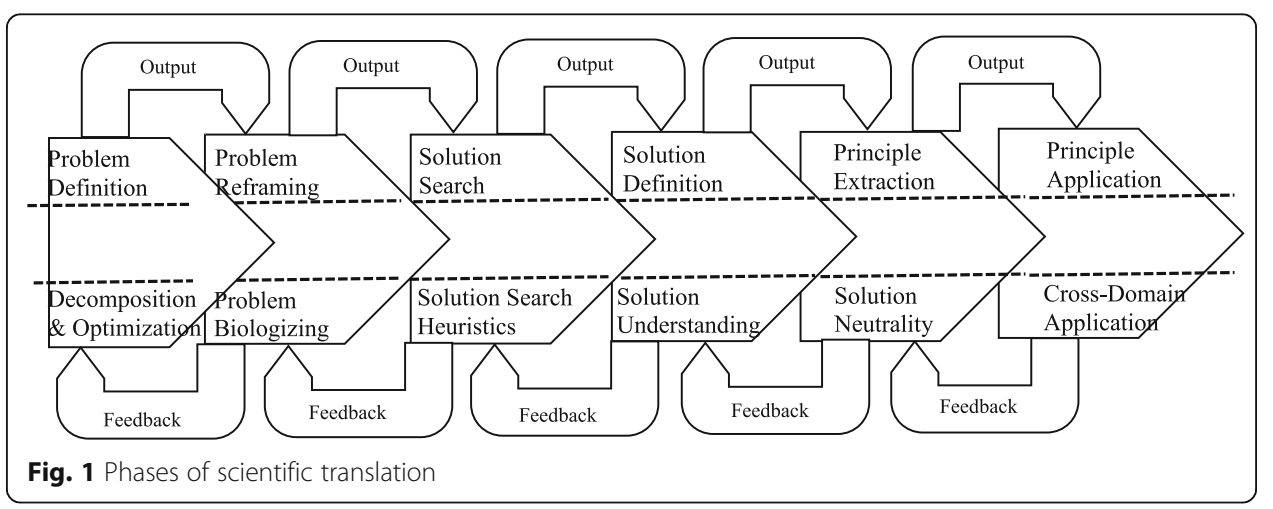


As illustrated by Fig. 1, a set of distinct and overlapping phases, each with various tasks, is supported by feed-forward processes (input) and recursive feedback processes when going from one phase to the next. This arrangement ensures that the updated problem definition reflects the learning and adjustments made. A series of iterations can take place between the individual phases. Engineers and biologists are the key actors involved in this dominant approach to the biomimetic translation phase. As can be seen from Fig. 1, biomimetic translations, from the point of view of learning and knowledge, involve convoluted and recursive processes of knowledge transfer and learning. As will be uncovered in the following discussion of the bombardier beetle case, biologists sometimes come across extraordinary functions or surface properties that may be so interesting that they are considered to have potential applications in a nonbiological context (i.e., for synthetic use).

Differently put, biologists may identify a biological design solution of potential use in a not-yet-acknowledged practical area of application-that is, a natural design solution 'looking for' an unidentified synthetic design problem. This phase is here termed the biomimetic idea phase (or pre-phase) and typically takes place before any attempt at scientific or engineering translations occurs. This phase may involve other scientific expertise beyond biology, such as physics. An idea for a specific application, however, sometimes surfaces before all the scientific details are accounted for. In such cases, an extended pre-phase of additional exploration is needed before the wider translation process can begin, as it is vital to adequately account for scientific principles behind the biomimetic design. Another phase, which is currently not included in the predominant phase-based model of biomimetic design, is commercial translation. Wanieck, Fayemi, Maranzana, Zollfrank, and Jacobs (2016) have conceptualized the biomimetics process from idea to market as a series of steps supported by tools. The same authors, however, also find that existing tools and techniques (they identified 43) are limited in that they tend to focus on the achievement of one specific goal rather than generic goals and thus fail to be applicable for a problem-driven approach in general (p. 54).

It has been argued that the aim of biomimetics is not to create exact analogues of biological systems, but to extract their design principles (Kennedy et al., 2015) at the system level. In a study of 20 biological systems from different areas, Sartori et al. (2010) identified four essential elements that seem to be involved in all the examined biomimetic creation processes. These processes included the formulation of search objectives, the search for biological analogues, analyses of identified analogues, and transference (p. 487). The researchers developed a model (SAPPhIRE) capable of capturing the functionality of the systems using physical phenomena to achieve goals. The test and analyses led to a generic biomimetic design process, a generic set of biomimetic transfer levels and a validated set of guidelines to encourage greater ideation fluency in the biomimetic design process (p. 501).

TRIZ has been introduced as a technique to generate innovative problem-solving. It is a system of problem-solving approaches based on abstract rules, with the aim of helping developers find good matches between biology and technology (Chechurin, 2016). Other studies have introduced a biomimetic taxonomy to help categorize the research interests of biomimetics (Hwang et al., 2015). El-Zeiny (2012) has developed a more focused design approach within the field of interior architecture, sketching out an entire analytical and 
problem-solving approach involving a set of distinct steps for problem-based and problem-solution approaches (p. 506). Zari (2017) has shown how biomimetic urban design can be applied in the design of service ecosystems for water and energy systems. In sum, the methodological repertoire of biomimetics seems to focus on scientific and technical translation, leaving commercial translation unaddressed.

\section{Methods}

The case is based on a literature review using the following words alone and in combination: natural design; biomimetics; biomimicry, scientific translation; and Bombardier Beetle. The literature search was done in Spring 2019 and a follow-up search during the review process in July 2020 in relation to my response to a comment from one of the reviewers. The following databases have been involved: Business Source Complete, ABI Inform Global, Scopus, and Web of Science.

This search not only helped retrieving the original scientific account of the Bombardier Beetle's unique properties with interesting translational potentials published by a physicist, but also it further identified the scientist that undertook the endeavour of performing the scientific translation, including finding the missing scientific pieces needed to see the whole picture. Our choice of case can be referred to as an extreme single case study (Onwuegbuzie, Collins, Leech, Dellinger, \& Jiao, 2010), that is a case that is extreme both in terms of potential (taken the size of the animal into consideration) and time from scientific recognition, over scientific translation and towards commercial translation. It further allows to exhibit-in a real case-all three phases of translation, from the scientific translation (providing the scientific explanation behind the beetle's unique feature), over a technical translation, involving solving a missing piece in the understanding needed for a commercial translation and to the commercial translation itself. The author's first involvement in this biomimetic translation case dates back several years to the supervising of two MSc students in finance and international business ${ }^{4}$. Their thesis examined the specific business model approach developed by Lars Uno Larsson and applied in his business venture, Swedish Biomimetics $3000^{5}$. Lars Uno Larsson recruited both students, and they became involved in developing new commercial applications of the platform technology translated from the bombardier beetle. Platform technology refers to the idea of families of technologies with a common underlying logic rather than to portfolios of unrelated activities (Sawhney, 1998). The selection of the bombardier beetle case is grounded in the following. First, the scientific translation of the beetle's spray technique is particularly unique, as the process of working out a thorough explanation of the physics involved in this spray technique stretched over several decades of scientific exploration and explanation. It perfectly illustrates the importance of finalizing scientific understanding during an extended pre-phase prior to finalizing the scientific and technical translation and subsequently commencing commercial translation. Second, the case involves the translation of a highly efficient function, a unique predator-defensive capability of bombardier beetles, showing that even very

\footnotetext{
${ }^{4 ‘}$ Exploring Biomimetic Business Development (A Case Study of Swedish Biomimetics 3000)'. A Thesis submitted for the Degree of Master of Science (Finance and International Business) at Aarhus University, School of Business and Social Sciences.

${ }^{5}$ The company has been a recipient of the Times Higher Education Award for 'Outstanding Contribution to Innovation and Technology'.
} 
small or specialized features of insects, for example, may represent a highly generic and commercial potential. Third, this case involves biomimetic translation that has been subjected to a successful commercial translation and invites the consideration of ways to accelerate commercial translation to extend the application of biomimetics to pharma and medical sectors. Finally, yet importantly, the beetle's spray technique appears to be extraordinarily energy efficient and thus superior to any known synthetic alternatives.

\section{Results: the Bombardier beetle case-from scientific exploration and theoretical explanation towards practical and commercial exploitation}

Little as they may share in common, both scientists and entrepreneurs are acknowledged for being intrinsically motivated and strongly driven by their ideas. While the former is typically driven by altruistic objectives (i.e., producing new scientific insights for the benefit of society), the latter tend to be sparked by a desire to solve a practical problem (i.e., producing a new business activity). Scientific advancements may be triggered by identified anomalies-phenomena not yet described or inadequately accounted for. Entrepreneurial activities in turn may spring from a market failure (loss of social welfare) or a market opportunity (a new or insufficiently serviced market need). In cases of entrepreneurial breakthroughs, not all entrepreneurs settle with their first successful business venture. Rather, some entrepreneurs keep looking for new opportunities and become serial entrepreneurs (Wright, Robbie, \& Ennew, 1997, p. 256).

The long and winding road to the scientific discovery and complete understanding of the bombardier beetle's defence technique is, however, quite fascinating. For more than half a century, it was known that these beetles had a phenomenal ability to defend themselves against predators by ejecting a series of non-random, visible jet-like sprays. Eisner (1958) examined the specific conditions that activated the discharge of hot liquid and the repellent function of the spray. He carried out a number of experiments during which the beetles were exposed to a series of controlled and traumatic stimuli as well as to direct predator attacks. He realized from his experiments that this protective device demonstrated an unusual effectiveness (p. 219), which led him to suggest that it would be interesting to understand the scientific principles of this spray mechanism in more detail ${ }^{6}$. Nevertheless, it was not until the late 2000s that scientists were capable of explaining all the scientific principles involved in the spray technique (Beheshti \& Mcintosch, 2007) and published the missing pieces that completed the scientific puzzle.

The essence of this scientific problem-solving can be summarized as follows: Having examined the results of previous studies, the two scientists realized that the technique associated with the intake and exhaust mechanisms allowing for non-random and repeated steam explosions to be dispatched was insufficiently understood. By using numerical simulations, they revealed that the principle behind the cyclic water injection accompanied by a water and steam decompression explosion was in fact the basic mechanism used by the beetle to dispatch non-random and repeated ejections. The principles underlying the spray technique were summarized in the following way: 'behind the remarkable repeated mass ejection efficiency is a steam explosion from saturated water, where the pressure relief exit valve plays a key role as the addition of sudden decompression causes the boiling liquid and steam to move out of the moveable rear nozzle. The exit nozzle diameter plays an important role in

${ }^{6} \mathrm{He}$ later (1966) published his research (with a colleague) in Science, 153(3742). 
optimizing the exit velocity, and the heat content reaching a specified target distance' (p. 64). At the end of their paper, however, the authors explicitly mentioned that this amazing mechanism holds promise for great biomimetic advantage and envisioned its future application to gas turbine igniters in the aerospace industry. This work was first reported at various conferences and later in a scholarly journal (cf. Beheshti \& Mcintosch, 2007). Having successfully documented the physics of the beetle's spray technique, the scientists suggested a portfolio with interesting potential for commercial exploitation. Although the researchers originally pointed primarily towards a possible application of the technique to gas turbine igniters in the aerospace industry, they also expected other applications to surface (Beheshti \& Mcintosch, 2007).

The story would probably have ended here, as indeed some biomimetic translations do, had Mcintosch and a Swedish serial entrepreneur, Lars Uno Larsson, not met during a conference presentation at which the missing scientific piece was presented. A further examination of this case serves to identify the innovative and commercial potential from actively applying biomimetics to launch marketable offerings. This case is particularly interesting because it also allows for the identification of some critical determinants associated with efficient commercial translation of biomimetics. The superior predator defence system identified in bombardier beetles became a direct source of bio-inspiration to the entrepreneur and the following phase of commercial exploitation. In the early 2000s, the venture resulted in the formation of a company to develop and grow the translation further. More specifically, the scientific principle behind the natural combustion technique that the beetle uses to deliver periodic sprays was patented. The meeting between Mcintosch and Larsson led to a close collaboration between Leeds University and the business venture Swedish Biomimetics 3000 (founded in 2004). The focus of the venture was to bring new biomimetics products to the market via a model they had developed for innovation acceleration (Swedish Biomimetics 3000, 2018).

The resulting R\&D activities associated with this developed and well-protected technological platform for the spray system technology involved, among others, fuel injection, fire extinguishers and fire suppression, all of which were facing major challenges as users and policymakers demanded even better performance and reduced environmental impact (Swedish Biomimetics 3000, 2018, p.35). Key determinants involved during the commercial translation include (i) entrepreneurial agency and resources (an experienced entrepreneur, commercial experiences and funding), (ii) cross-sectional collaboration (collaboration between university scientists and a serial entrepreneur), (iii) patents (securing intellectual property rights), (iv) an effective business $\operatorname{model}^{7}$, and (v) focus on new commercial applications based on platform technology. In the words of the founding entrepreneur, the case is an outcome of the developed model of translation, based on interdisciplinary concepts, ideas and cultures, with the objective of funding and fostering an environment allowing immediate short-term and long-term futuristic technologies to materialize and become commercial candidates (Larsson, 2007).

\footnotetext{
${ }^{7}$ In the Swedish Biomimetics 3000 case, the formation of a new company was chosen as a means for hosting the activities associated with commercializing the spray technique; there may, however, be other situations in which the commercial agent can host the commercialization of the biomimetic translation in an existing firm.
} 


\section{Discussion: speeding up the process of commercialization}

Not only in the Bombardier case, but in other biomimetic cases as well, the biomimetic translation seems a rather 'slow' process. This is a well-known problem from the pharmaceutical and biotech sectors, where the translation from bench to bed often takes many years. A few notable exceptions, however, may offer some helpful inspiration to reduce time of translation from theoretical application to practical (business) applications. The diversity of natural products' structures and their derivatives has long been acknowledged as an important source of new pharmaceuticals (Newman \& Craig, 2007). Biomimetics is therefore not restricted to being used only for buildings or other traditional industrial artefacts or materials. Rather, biomimetics also holds translational potential for the health and pharma sectors. In cases of pharmaceutical- and health sector-based translations, however, the speed of translation becomes of particular importance. In consequence, it is necessary to borrow from literature on translational research in medicine. A review of over 100 papers in the most impactful science journals from 1979 to 1983 (papers with clear promises of major clinical applicative potential) revealed that only about $5 \%$ were in licensed clinical use two decades later (Ioannidis, 2004). Considering the traditional basic science-funding approach in the biotech and pharma sectors, quite a bit of untargeted research funding is put in at one end of the sequential-based discovery process, and investors wish or hope that after quite some years new and useful commercial applications will eventually come out the other end. It is probably also safe to assume that what governs the behaviour of the scientists involved in this model tends to be influenced more by academic traditions and norms on the one hand and personal career considerations on the other than by the interests of patients and/or the industry.

A successful translation from pre-clinical research (a new biological discovery) to the clinical stage (a new drug) involves a variety of components and partnerships (Simon, 2008). The process of how a new scientific insight is translated into new marketable applications deserves particular attention. This shift in the way drugs are produced has been described as a paradigm shift (Curry, 2008). The translation of basic scientific discoveries into new clinical applications while scientific questions are fed back based on clinical trials has been referred to as translational research (Sugerman \& McKenna, 2003). Experiences from innovations in translational research may therefore offer some useful insights. A notable example of how to step up the process of translation has been introduced by the non-profit Myelin Repair Foundation ${ }^{8}$ and its ability to accelerate the time from lab to practical use. The translation model works as a shared road map and is based on parallel research. Moreover, it makes rapid iterations possible, speeding up the joint review of progress and exchange of experiences. This approach to scientific translation has been described as a reconceptualization of the organization of scientific research in the field of basic drug discovery to accelerate new treatment for myelin repair (Carlile \& Lakhani, 2011, p. 9). They noted that when the Myelin Repair Foundation was established, a paradox emerged. While the number of scientific papers had increased by a factor of eight, scientists were increasingly focusing more and more

\footnotetext{
${ }^{8}$ A non-profit organization founded by Scott Johnson-http://www.myelinrepair.org/about/scott_johnson. shtml. Myelin is an important and insulating wrapping around nerve cells. If the myelin wrapping is damaged, it has serious effects on the nerves' ability to conduct electrical impulses as they are designed to do. If not repaired, the nerves may die.
} 
narrowly on their research. A key reason for this, they argued, had to do with the academic schemes of incentives and rewards (p. 19). Second, they found that by focusing on repair (hence the name) rather than a cure, the research approach turned into a sweet spot, allowing them to address the challenges of high novelty in a highly researched but poorly understood disease (p. 21).

Business models that are grown out of non-profit foundations such as the Myelin Repair Foundation (Petsko, 2006) have introduced an accelerated research collaboration model-or in the terminology of the Foundation, the 'ARC model'. By using a businessscience hybrid model for medical research to circumvent what the inventor and founder, Scott Johnson, perceived as the barriers inherent in the traditional medical research model (Petsko, 2006), it is possible to accelerate the process from bench to bed. The Myelin Repair Foundation focuses exclusively on knowledge associated with how myelin is created, damaged and repaired. The accelerated translation process allows for rapid sharing of new findings and for coordinating simultaneous research projects, accelerating the time involved in the discovery and validation of myelin repair treatments. The model is sketched out in Fig. 2 below:

According to the Myelin Repair Foundation, the road map has a time frame of 5 years. Key elements in the framework include (i) an advisory board made up of prominent advisors from science and commerce, (ii) inter-university collaboration, (iii) parallel R\&D, (iv) open innovation, (v) fast iterations, and (vi) shared learning (and intellectual property). The advisory board is responsible for the design, focus and update of the research plan. The board of directors is involved in managing the oversight of the staff, budget and fundraising. The staff and support infrastructure ensure that the participating and collaborating labs and scientists are wired via an IT infrastructure. The key scientists (Principal Investigators) ${ }^{9}$ are responsible for identifying and generating novel approaches as well as confirming their value (Carlile \& Lakhani, 2011). The Foundation further explains that the established infrastructure has been put in place to secure a smooth and ongoing interaction and data exchange. It also provides a business support staff. Shared IP conduct regularly reviews and connects all participants virtually and handles critical IP for patent protection. Finally, royalties handle return income generated from patents to the foundation from involved universities and scientists to fund future research within the foundation's business area.

Contrary to the traditional single investigator-driven model, the ARC model presented above incorporates the efforts of multiple investigators into a shared and collaborative arrangement, which allows for establishing a focus on parallel outcomes. In combination with fast iterations as the collaborating scientists review each other's results and refine their approaches based on this shared model of learning, the time required for research to generate promising discoveries is compressed significantly (Hagel \& Brown, 2008). In return, the participating scientists commit to sharing their results (both successes and failures) immediately across the participating labs prior to publication (Johnson, 2011, p. 24). Moreover, to handle the differences in tech-trans rules across labs, the foundation has also put in place a framework that can handle the agreement between partners (Institute of Medicine, 2010, pp. 32-33). A few key features

${ }^{9}$ The founder had ex ante compiled a list of academic scientists with documented research in the myelin arena and was highly productive, had specialized in various aspects of multiple sclerosis and had a reputation for collaboration leading to five high-profile scientists (ibid., p. 22) 


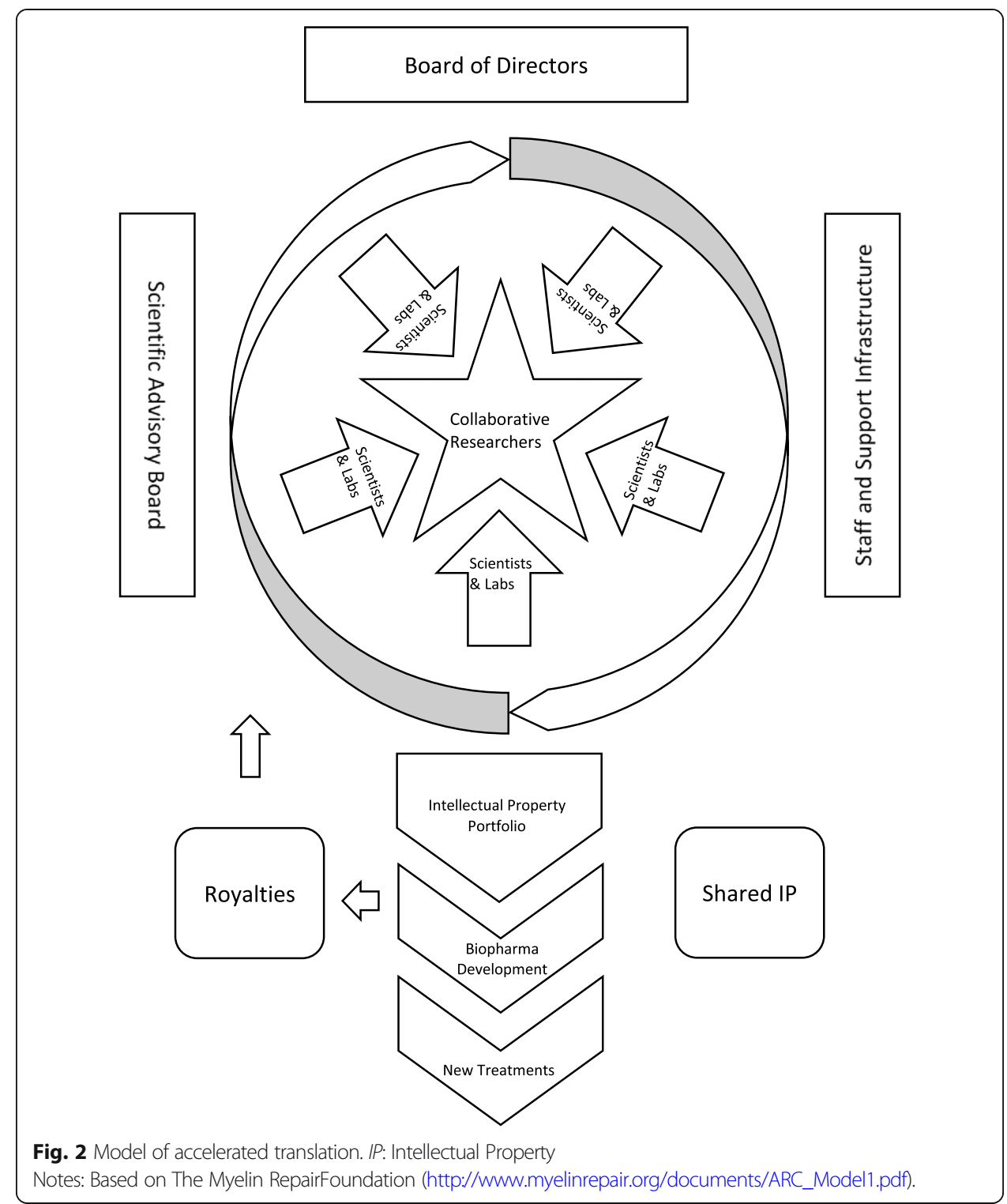

of this collaborative model of scientific translation, among others, have been singled out as particularly critical for the success of the ARC model (Carlile \& Lakhani, 2011). One is the possibility of sharing hypotheses and testing criteria, dosage rates and data. Another important feature is the choice of turning the focus from a cure approach to a treatment approach (p. 21).

The application of natural design for synthetic design problems or for meeting new and unserved needs also holds interesting potential for contributing to responsible management practices in more than one meaning of the word. First, from a common-sense responsibility point of view, it can be argued that the use of biomimetics in the context of innovation management may prevent the spending of unnecessary time and money by reducing the costs and efforts required to come up with a useful synthetic design from scratch if a biomimetic alternative already exists. Second, in relation to the environmental 
dimension of responsible management, biomimetics has been found to be capable of contributing to environmental sustainability. Recently, topics such as artificial photosynthesis (Sherman et al., 2013), green electronics based on nature-inspired materials (Irimia-Vladu, 2014), and solutions for environmental sustainability and medicine (Fernandez \& Ingber, 2013) have been singled out as environmentally responsible uses. Furthermore, biomimetics has been used for the design of more efficient building skins (Radwan \& Osama, 2016) and ceiling structures (Antony, Griesshammer, Speck, \& Speck, 2014).

Embracing biomimetics and translational research as important and highly relevant research fields in business studies has yet to materialize on a larger scale. In spite of the widespread scientific recognition of translational research (Wehling, 2005), only a few empirical studies have been identified in the management literature (Cremades et al., 2015). This lack of interest in management and business studies, as documented in this study, is even more pronounced with regard to biomimetics. This would hardly be surprising had there been no previous tradition in organization and management theory with regard to borrowing from biology. This, however, is not quite the case. First, from the point of view of theory development, the idea of borrowing from biology has been used over several decades. In fact, this was proposed long ago (Hrebiniak \& Joyce, 1985; Shin \& Konrad, 2014; von Bertalanffy, 1972) and has been foundational for the open systems perspective on organizations (Lawrance \& Lorsch, 1967). It is based on the argument that the design of an organization and the outcome of its activities are contingent on the environment and on the organization's ability to meet integration and differentiation requirements according to its environment. Population ecology is another influential example. This concept was introduced to account for organization-environment relationships and the role of variation and natural selection processes (Hannan \& Freeman, 1977).

Because few to no linkages between biomimetics and management research exist, possible bridges will have to come from other directions. One interesting possibility could be the long-expressed interest into the moral dimensions of management. Humans use ethics and morals to judge the social and individual 'rightness' of rules and conduct. Ethics have therefore often been used as an implicit justification for a given decision. This is also acknowledged in management theory. Chester Barnard, for example, was one of the early contributors to the moral foundation of business and associated decision-making activities by acknowledging the moral dimension of cooperation and a collective purpose (Barnard, 1938), as well as organizational morality and business stakeholders (Barnard, 1958). In his book, he posits, 'The inculcation of belief in the real existence of a common purpose is an essential executive function. It explains much educational and so-called morale work...' (p. 38). Others, however, have presented the following as an 'excuse' for not acting morally responsible: 'The ethical position of the manager is, indeed, difficult. The underlying philosophy of business is, as we have seen, unethical, the primary consideration being the efficient use of resource' (Duddy, 1945, p. 71).

Opponents of this view, however, have also surfaced. Levitt (1958), for example, gave explicit warnings of the potential dangers associated with social responsibility. Nonetheless, Barnard maintained that a manager's responsibility also includes moral considerations and ethical dimensions, or as he puts it, 'management decisions are concerned with moral issues' (Barnard, 1958, p.2). Regarding the latter, Barnard referred to moral issues as beliefs or feelings about what is right or wrong regardless of self-interest. What is also 
interesting to note from the early days of responsible management is that Barnard, contrary to the mainstream efficiency excuse, points to increased specialization, especially in economic activities and in the machinery and materials which are employed for materialistic purposes' (p. 12), as an example of directing the attention towards scientific and technical issues rather than to moral ones.

\section{Conclusion and implications}

Embracing biomimetics and translational research as important and highly relevant research fields in business studies has yet to materialize on a larger scale. In spite of the widespread scientific recognition of translational research (Wehling, 2005), only a few empirical studies have been identified in the management literature (Cremades et al., 2015). This lack of interest in management and business studies, as documented in this study, is even more pronounced with regard to biomimetics. This would hardly be surprising had there been no previous tradition in organization and management theory with regard to borrowing from biology. This, however, is not quite the case. First, from the point of view of theory development, the idea of borrowing from biology has been used over several decades. In fact, this was proposed long ago (Hrebiniak \& Joyce, 1985; von Bertalanffy, 1972) and has been foundational for the open systems perspective on organizations (Lawrance \& Lorsch, 1967). It is based on the argument that the design of an organization and the outcome of its activities are contingent on the environment and on the organization's ability to meet integration and differentiation requirements according to its environment. Population ecology is another influential example. This concept was introduced to account for organization-environment relationships and the role of variation and natural selection processes (Hannan \& Freeman, 1977). Differently put, the idea of borrowing (concepts) from 'nature' should not be entirely unknown in the field.

This study has important research repercussions as well as practical implications for biomimetic translation and for responsible management practices. It extends a longstanding, established practice in the management and business theory of borrowing from biology. The paper identifies important imperfections in the existing theory on biomimetic translation, which prevent the existing theory from accounting adequately for what happens when biomimetics moves from scientific to commercial translation. Not all biomimetic innovations are necessarily ripe for entering the mainstream-stage phase model of translation; rather, additional details need to be clarified during prephase exploration before proceeding to the translational process. This pre-phase needs to be acknowledged and included in the existing translational model of biomimetics so that it adequately depicts all processes of translation. Furthermore, and more importantly, the commercial phase (involving entrepreneurial agency) is left out of the existing model of biomimetic translation. This study, however, goes beyond identifying imperfection by proposing concrete tactics for correcting the identified imperfections.

As was evident from the examination and discussion of the bombardier beetles' spray technique, commercialization involves not only cross-domain but also cross-sector activities and collaboration across science and business, and a different focus (value propositions and choice of business model) emphasizing the need for new actors (entrepreneurs and venture capitalists in the translation process. The transition from the scientific and technical phases to the commercial phase appears to represent a 
potential bottleneck. It invites the bringing in of new actors (entrepreneurs) with documented business interests and competences in the biomimetic translation process. The commercial phase also involves critical decisions with different implications and high uncertainty and risks. In the case of a more generic approach to commercial translation, a platform development approach is an obvious choice to consider. This would imply hosting in-house capabilities to assist in the further commercialization of the platform technologies owned (as in the case of Swedish Biomimetics 3000, 2018). Another barrier that needs to be overcome before a more attractive business case can be proposed is the development of quantifiable performance indicators applicable in a cost-benefit framework. Until recently, no quantification tools have been regarding quantifying biomimetic performance (Terrier, Glaus, \& Raufflet, 2019). Recently, however, a few interesting developments have surfaced such as the built environment sector (Hayes, Desha, \& Gibbs, 2019), data center performance (Kubler, Rondeau, Georges, \& Mutua, 2019) and a more generic approach trying to incorporate the life principles of Benyus as the basis for the development of 'biomiMETRIC assistance tool, the objective of which is to provide a quantification approach to each principle and a measurement indicator to assess biomimetic performance' and thus as part of a conventional design process (Terrier et al., 2019, p. 16).

The bombardier case further underscores the importance of venture capital and riskwilling entrepreneurial agency. Other obstacles, however, can act as brakes on commercialization, such as competing technology, product, or service development or the lack of an appropriate business model, property rights, or regulation. The commercial side of scientific translation may begin with entrepreneurs securing the intellectual property in question (Curry, 2008). If the involved biomimetic scientists, for example, either do not wish for or do not succeed in teaming up with one or more entrepreneurs, the situation suggests that they will need venture capital as well as network and commercial expertise, which an affiliation with a business incubator can typically provide (Bøllingtoft and Ulhøi 2005). The formation of a new start-up, however, is not a prerequisite for a successful commercial translation. Rather, the choice of business model approach requires particular attention prior to the commercial translation. Similarly, entrepreneurial agency may come from an existing firm and does not automatically involve the formation of a new firm. More research is needed to adequately understand the links between the commercialization of biomimetics and ways in which to speed up the translation process of scientific discoveries, along with their implications for business model design.

In terms of the practical implications for future engineers, designers and innovation managers, business schools and educators assume a relevant role and responsibility with regard to promoting biomimetics as an alternative design paradigm. Society trust such institutions and actors to educate the next generations of managers. This responsibility implies that students should not be met by a myopic and distorted view of their future roles and responsibilities as authoritative decision-makers-for example, being exposed to only maximizing shareholder value at the expense of all other stakeholders. Educators can therefore contribute to ensuring that biomimetics becomes both more widely disseminated and generally acknowledged as a possible design source. This may even offer classic design advantages. The study of de Pauw, Karana, Kandachar, and Poppelaars (2014), for example, is interesting in this context, as it compared 
biomimicry with the traditional eco-design approach and found that biomimicry tends to broaden the solution space of the designer during the design process (p. 182). This suggests that students were given increased opportunities during the learning process to critically assess and evaluate relevant aspects.

The study establishes that the efficient translation of biomimetics involves the critical processes of exploration, explanation and exploitation. It further identifies critical and greatly understudied translational processes by showing that existing translation models are inefficient and incomplete. The paper singles out techniques for correcting existing translational flaws and bridges to responsible management practices. In so doing, the paper has answered the three questions posed in the beginning. The answer to the first research question, what do designs in nature have to offer in relation to synthetic innovation (i.e., what makes natural design unusual or different from synthetic design), is that biomimetics holds interesting potential for use in innovation management. Applying biomimetics as a key source of input in the innovation management process is unusual and breaks with the existing paradigm, as it seeks to translate natural designs into cross-domain and ad hoc synthetic design solutions.

In dealing with the second research question-addressing the essential factors during the commercial translation process of natural designs-the paper documents that commercial translation is greatly understudied, but is nonetheless an essential element for an effective biomimetic translation process. In trying to fill this important research gap (the lack of focus on the commercialization process of biomimetic translations), some specific tactics have been identified. From the examined case study, essential factors of key importance include entrepreneurial agency, cross-sectional collaboration, intellectual property protection, an appropriate business model, company formation and a platform technology focus.

Abbreviations

USD: American Dollars; SAPPhIRE: State-Action-Part-Phenomenon-Input-oRgan-Effect; PI: Principal Investigator

Acknowledgements

The author appreciates comments and suggestions made by Dr S. Nørskov to an earlier version of this paper.

Author's contributions

The author read and approved the final manuscript.

Funding

No funding (beyond my university-paid professorship) has been involved in this work.

Availability of data and materials

Not applicable. Data sharing is not applicable to this article as no datasets were generated or analyzed during the current study.

Competing interests

The author declares that he has no competing interests.

Received: 8 December 2019 Accepted: 26 October 2020

Published online: 11 January 2021

References

Antony, F., Griesshammer, R., Speck, T., \& Speck, O. (2014). Sustainability assessment of a lightweight biomimetic ceiling structure. Bioinspiration \& Biomimetics, 9, 1-15 https://iopscience.iop.org/article/10.1088/1748-3182/9/1/016013/meta.

Autumn, K., Liang, Y. A., Hsieh, S. T., Zesch, W., Chan, W. P., Kenny, T. W., ... Full, R. J. (2000). Adhesive force of a single gecko foot-hair. Nature, 405, 681-685 https://doi.org/10.1038/35015073.

Bach, D., Schmich, F., Masselter, F., \& Speck, T. (2015). A review of selected pumping systems in nature and engineering Potential biomimetic concepts for improving displacement pumps and pulsation damping. Bioinspiration \& Biomimetics, 10, 1-28 https://doi.org/10.1088/1748-3190/10/5/051001. 
Bae, W.-G., Kim, H. N., Kim, D., Park, S.-H., Jeong, H. E., \& Suh, K.-Y. (2014). 25 ${ }^{\text {th }}$ anniversary article: Scaleable multiscale patterned structures inspired by nature: The role of hierarchy. Advanced Materials, 26(5), 675-700 https://doi.org/10.1002/ adma.201303412.

Barnard, C. I. (1938). The functions of the executive. Cambridge: Harvard University Press.

Barnard, C. I. (1958). Elementary conditions of business morals. California Management Review, 1(1), 1-13 https://doi.org/10. $2307 / 41165329$

Barthlott, W., \& Neinhuis, C. (1997). Purity of the sacred lotus, or escape from contamination in biological surfaces. Planta, 202(1), 1-8 https://doi.org/10.1007/s004250050096.

Beheshti, N., \& Mcintosch, A. C. (2007). The bombardier beetle and its use of a pressure relief valve system to deliver a periodic pulsed spray. Bioinspiration \& Biomimetics, 2, 57-64 https://doi.org/10.1088/1748-3182/2/4/001.

Bensaude-Vincent, B., Arribart, H., Bouligand, Y., \& Sanchez, C. (2002). Chemist and the school of nature. New Journal of Chemistry, 26(1), 1-5. https://doi.org/10.1039/B108504M.

Benyus, J. M. (1997). Biomimicry: Innovation inspired by nature. New York: Harper Perennial.

Blok, V., \& Gremmen, B. (2016). Ecological innovation: Biomimicry as a new way of thinking and acting ecologically. Journal of Agricultural Environmental Ethics, 29, 203-217 https://doi.org/10.1007/s10806-015-9596-1.

Bøllingtoft, A., \& Ulhøi, J. P. (2005). The networked business incubator: leveraging entrepreneurial agency? (with A. Bøllingtoft). Journal of Business Venturing, 20(2), 265-290.

Carlile, P. R., \& Lakhani, K. R. (2011). Innovation and the challenge of novelty: The novelty-confirmation-transformation cycle in software and science. Working paper 11-096. Boston: Harvard Business School.

Chechurin, L. (2016). TRIZ in science. Reviewing indexed publications. Procedia CIRP, 39, 156-165 https://doi.org/10.1016/j. procir.2016.01.182.

Cremades, E., Balbastre-Benavent, F., \& Domínguez, E. S. (2015). Managerial practices driving knowledge creation, learning and transfer in translational research: An explorative case study. R\&D Management, 45(4), 361-385 https://doi.org/10.1111/ radm. 12081.

Curry, S. H. (2008). Translational science: Past, present, and the future. BioTechniques for Preclinical Development, 44(2), i-viii https://doi.org/10.2144/000112749.

de Pauw, I. C., Karana, E., Kandachar, P., \& Poppelaars, F. (2014). Comparing biomimicry and cradle to cradle with ecodesign: A case study of student design projects. Journal of Cleaner Production, 78, 174-183 https://doi.org/10.1016/j.jclepro.2014.04.077.

Duddy, E. A. (1945). The moral implications of business as a profession. Journal of Business of the University of Chicago, 18(2), 63-72.

Eisner, T. (1958). The protective role of the spray mechanism of the bombardier beetle. Brachynus ballistarius Lec Journal of Insect Physiology, 2, 215-220.

El-Zeiny, R. M. A. (2012). Biomimicry as a problem solving methodology in interior architecture. Procedia-Social and Behavioral Sciences, 50, 502-512 https://doi.org/10.1016/j.sbspro.2012.08.054

Fernandez, J. G., \& Ingber, D. E. (2013). Bioinspired chitinous material solutions for environmental sustainability and medicine. Advances in Functional Materials, 23, 4454-4466 https://doi.org/10.1002/adfm.201300053.

Fewell, J. H. (2015). Social biomimicry: What do ants and bees tell us about organization in the natural world? Journal of Bioeconomics, 17(3), 207-217 https://doi.org/10.1007/s10818-015-9207-2.

Fisch, M. (2017). The nature of biomimicry: Toward a novel technological culture. Science, Technology \& Human Values, 42(5), 795-821 https://doi.org/10.1177/0162243916689599.

García-Serna, J., Pérez-Barrígon, L., \& Cocero, M. J. (2007). New trends for design towards sustainability in chemical engineering: Green engineering. Chemical Engineering Journal, 133, 7-30 https://doi.org/10.1016/j.cej.2007.02.028.

Global Market Insight (2018). https://www.gminsights.com/pressrelease/medical-biomimetics-market. Accessed 2 Jan 22018.

Habib, M., \& Watanabe, W. (2012). Bioinspiration and emerging actuator technologies. Artificial Life Robotics, 17, 1991-1196 https://doi.org/10.1007/s10015-012-0037-1.

Hagel, J., \& Brown, J. S. (2008). Myelin Repair Foundation's institutional innovation. Bloomberg Businessweek http://www. businessweek.com/innovate/content/may2008/id2008057_399178.htm. Accessed 11 Sep 2010.

Hannan, M. T., \& Freeman, J. H. (1977). The population ecology of organizations. American Journal of Sociology, 82(5), 929-964 https://doi.org/10.1086/226424.

Hayes, S., Desha, C., \& Gibbs, M. (2019). Findings of case-study analysis: System-level biomimicry in built-environment design. Biomimetics, 4, 73

Helms, M., Vattam, S. S., \& Goel, A. K. (2009). Biologically inspired design: Process and products. Design Studies, 30(5), 606-622 https://doi.org/10.1016/j.destud.2009.04.003.

Hrebiniak, L. G., \& Joyce, W. F. (1985). Organizational adaptation: Strategic choice and environmental determinism. Administrative Science Quarterly, 30(3), 336-349 https://doi.org/10.2307/2392666.

Hu, Y., Liu, J., Chang, L., Yang, L., Xu, A., Qi, K., .. Wu, Y. (2017). Electrically and sunlight-driven actuar with versatile biomimetic motions based on rolled carbon nanotube bilayer composite. Advanced Functional Materials, 27(44), 1-10 https://doi.org/10.1002/adfm.201704388.

Hwang, J., Jeong, Y., Park, J. M., Lee, K. H., Hong, J. W., \& Choi, J. (2015). Biomimetics: Forecasting the future of science, engineering, and medicine. International Journal of Nanomedicine, 10, 5701-5713 https://doi.org/10.2147/IJN.S83642.

Institute of Medicine (2010). Extending the spectrum of precompetitive collaboration in oncology research: workshop summery. Washington, DC: The National Academies Press.

loannidis, J. P. A. (2004). Materializing research promises: Opportunities, priorities and conflicts in translational medicine. Journal of Translational Medicine, 2(5), 1-6 https://doi.org/10.1186/1479-5876-2-5.

louguina, A., Dawson, J. W., Hallgrimson, B., \& Smart, G. (2014). Biologically informed disciplines: A comparative analysis of bionics, biomimetics, biomimicry, and bio-inspiration among others. International Journal of Design and Nature, 9, 197205 https://doi.org/10.2495/DNE-V9-N3-197-205.

Irimia-Vladu, M. (2014). Green electronics: Biodegradable and biocompatible materials and devices for sustainable future. Chemical Society Reviews, 43, 588-610 https://doi.org/10.1039/c3cs60235d. 
Jang, W.-D., Selim, K. M. K., Lee, C.-H., \& Kang, I.-K. (2008). Bioinspired application of dendrimers: From bio-mimicry to biomedical applications. Progress in Polymer Science, 34, 1-23 https://doi.org/10.1016/j.progpolymsci.2008.08.003.

Johnson, S. (2011). Partnering for a cure. Stanford Social Innovation Review, 9(4), 23-24.

Kennedy, E., Fecheyr-Lippens, D., Hsiung, B.-K., Niewiarowaki, P. H., \& Kolodziej, M. (2015). Biomimicry: A path to sustainable innovation. Design Issues, 31(3), 656-673 https://doi.org/10.1162/DESI_a_00339.

Kim, W., \& Busch, J. W. M. (2012). Natural drinking strategies. Journal of Fluid Mechanics, 705, 7-25 https://doi.org/10.1017/jfm. 2012.122.

Kubler, S., Rondeau, É., Georges, J.-P., \& Mutua, P. L. (2019). Benefit-cost model for comparing data center performance from a biomimicry perspective. Journal of Cleaner Production, 231, 817-834.

Larsson, L. (2007). Funding and fostering of translational research of biomimetic concepts to the point where they are considered commercial candidates. Comparative biochemistry and physiology. Part a. Molecular \& Integrative Physiology, 146(4), S137 https://doi.org/10.1016/j.cbpa.2007.01.266.

Lawrance, P. R., \& Lorsch, J. W. (1967). Differentiation and integration in complex organizations. Administrative Science Quarterly, 12(1), 1-47 https://doi.org/10.2307/2391211.

Lepora, N. F., Verschure, P., \& Prescott, T. J. (2013). The state of the art in biomimetics. Bioinspiration \& Biomimetics, 8, 1-11.

Levitt, T. (1958). The dangers of social responsibility. Harvard Business Review, 36(5), 41-50.

Lurie-Luke, E. (2014). Product and technology innovation: What can biomimicry inspire? Biotechnology Advances, 32, 14941505 https://doi.org/10.1016/j.biotechadv.2014.10.002.

Mak, T., \& Shu, L. (2008). Using descriptions of biological phenomena for idea generation. Research in Engineering Design, 19(1), 21-28 https://doi.org/10.1007/s00163-007-0041-y.

Newman, D. J., \& Craig, G. M. (2007). Natural products as sources of new drugs over the last 25 years. Journal of Natural Products, 70(3), 461-477 https://doi.org/10.1021/np068054v.

Onwuegbuzie, A. J., Collins, K. M. T., Leech, N. L., Dellinger, A. B., \& Jiao, Q. G. (2010). A meta-framework for conducting mixedmethods research syntheses for stress and coping research and beyond. In K. T. M. Collins, A. J. Onwuegbuzie, \& Q. G. Jiao (Eds.), Toward a broader understanding of stress and coping, (pp. 169-212). Charlotte: Information Age Publisher, Inc..

Petsko, G. (2006). A model worth considering? Genome Biology, 7(12), 121 https://doi.org/10.1186/gb-2006-7-12-121.

Radwan, G. A. N., \& Osama, N. (2016). Biomimicry: An approach for energy efficient building skin design. Procedia Environmental Sciences, 34, 178-189 https://doi.org/10.1016/j.proenv.2016.04.017.

Rawlings, A. E., Bramble, J. P., \& Staniland, S. S. (2012). Innovation through imitation: Biomimetic, bioinspired and biokleptic research. Soft Matter, 8, 6675-6679 https://doi.org/10.1039/C2SM25385B.

Rice, J., \& Martin, N. (2007). Using biological models to improve innovation systems. European Journal of Innovation, 10(2), 201-214 https://doi.org/10.1108/14601060710745251.

Salgueiredo, C. F., \& Hatchuel, A. (2016). Beyond analogy: A model of bioinspiration for creative design. Artificial Intelligence for Engineering Design, Analysis and Manufacturing, 30, 159-170 https://doi.org/10.1017/S0890060416000044.

Sartori, J., Pal, U., \& Chakrabarti, A. (2010). A methodology for supporting "transfer" in biomimetic design. Artificial Intelligence for Engineering Design, 24, 483-505 https://doi.org/10.1017/S0890060410000351.

Sawhney, M. S. (1998). Leveraged high-variety strategies: From portfolio thinking to platform thinking. Journal of the Academy of Marketing Science, 26, 54-61 https://doi.org/10.1177/0092070398261006.

Seeley, T. D. (2003). Consensus building during nest-site selection in honey bee swarms: The expiration of dissent. Behavioral Ecology and Sociobiology, 53(6), 417-424 https://doi.org/10.1007/s00265-003-0598-z.

Sherman, B. D., Vaughn, M. D., Bergkamp, J. J., Gust, D., More, A. L., \& Moore, T. A. (2013). Evolution of reaction center mimics to systems capable of generating solar fuel. Photosynthesis Research, 120, 59-70 https://doi.org/10.1007/s11120-013-9795-4.

Shin, D., \& Konrad, A. M. (2014). Causality between high-performance work systems and organizational performance. Journal of Management, 43(4), 973-997 https://doi.org/10.1177/0149206314544746.

Simon, R. (2008). Lost in translation: Problems and pitfalls in the translating laboratory observations to clinical utility. European Journal of Cancer, 44, 2707-2713 https://doi.org/10.1016/j.ejca.2008.09.009.

Sugerman, J., \& McKenna, W. G. (2003). Hurdles for translational research. Radiation Research, 160(1), 1-3.

Swedish Biomimetics 3000. http://www.swedishbiomimetics.com/pressrelease/IMPACT_Article.pdf. Accessed 14 Jan 2018.

Terrier, P., Glaus, M., \& Raufflet, E. (2019). BiomiMETRIC assistance tool: a quantitative performance tool for biomimetic design. Biomimetics, 4, 1-19.

Troncale, L. (2016). Beyond biomimicry to systems mimicry: Using evidence from the natural science to design better systems. INSIGHT, 19(1), 41-45 https://doi.org/10.1002/inst.12072.

Ulhøi, J. (2015). Framing biomimetics in a strategic orientation perspective. Technology Analysis \& Strategic Management, 27(3), 300-314.

Ulhøi, J. P., Bjerregaard, T., \& Neergaard, H. (2012). Beyond unidirectional technology transfer: an empirical study of trustbased university-industry research and technology collaboration (with T. Bjerregaard and H. Neergaard). International Journal of Entrepreneurship and Innovation, 13(3), 287-299.

Volstad, N. L., \& Boks, C. (2012). On the use of biomimicry as a useful tool for the industrial designer. Sustainable Development, 20, 189-199 https://doi.org/10.1002/sd.1535.

von Bertalanffy, L. (1972). The history and status of general systems theory. Academy of Management Journal, 15(4), 407-426 https://doi.org/10.2307/255139.

Wanieck, K., Fayemi, P.-E., Maranzana, N., Zollfrank, C., \& Jacobs, S. (2016). Biomimetics and its tools. Bioinspired, Biomimetic and Nanomaterials, 6, 53-66 https://doi.org/10.1680/jbibn.16.00010.

Wehling, M. (2005). Translational medicine: Can it really facilitate the transition of research "from bench to bed"? European Journal of Pharmacology, 62, 91-95 https://doi.org/10.1007/s00228-005-0060-4.

Wong, T. S., Kang, S. H., Tang, S. K., Smythe, E. J., Hatton, B. D., Grinthal, A., \& Aizenberg, J. (2011). Bioinspired self-repairing slippery surfaces with pressure stable omniphobicity. Nature, 477, 443-447 https://doi.org/10.1038/nature10447.

Wright, M., Robbie, K., \& Ennew, C. (1997). Serial entrepreneurs. British Journal of Management, 8, 251-268 https://doi.org/10. $1111 / 1467-8551.00064$. 
Zari, M. P. (2017). Biomimetic urban design: Ecosystems service provision of water and energy. Buildings, 7, 1-13 https://doi.org/10.3390/buildings7010021.

Zhang, J., Chen, W., Yang, M., Chen, S., Zhu, B., Niu, S., ... Wang, H. (2017). The ingenious structure of scorpion armor inspires sand-resistant surfaces. Tribology Letters, 65(110), 1-10.

\section{Publisher's Note}

Springer Nature remains neutral with regard to jurisdictional claims in published maps and institutional affiliations.

Submit your manuscript to a SpringerOpen ${ }^{\circ}$ journal and benefit from:

- Convenient online submission

- Rigorous peer review

- Open access: articles freely available online

- High visibility within the field

- Retaining the copyright to your article

Submit your next manuscript at $\boldsymbol{\nabla}$ springeropen.com 